NASA Technical Memorandum 105643

AIAA-92-4006

\title{
Description of a Pressure Measurement Technique for Obtaining Surface Static Pressures of a Radial Turbine
}

L. Danielle DiCicco and Brent C. Nowlin

National Aeronautics and Space Administration

Lewis Research Center

Cleveland, Ohio

and

Lizet Tirres

Sverdrup Technology, Inc.

Lewis Research Center Group

Brook Park, Ohio

Prepared for the

17th Aerospace Ground Testing Conference

sponsored by the American Institute of Aeronautics and Astronautics

Nashville, Tennessee, July 6-8, 1992

\section{N/SA}





\title{
DESCRIPTION OF A PRESSURE MEASUREMENT TECHNIQUE FOR OBTAINING SURFACE
}

\author{
STATIC PRESSURES OF A RADIAL TURBINE \\ L. Danielle DiCicco ${ }^{*}$ and Brent C. Nowlin \\ National Aeronautics and Space Administration \\ Lewis Research Center \\ Cleveland, Ohio 44135 \\ and \\ Lizet Tirres ${ }^{*}$ \\ Sverdrup Technology, Inc. \\ Lewis Research Center Group \\ Brook Park, Ohio 44142
}

\begin{abstract}
$\underline{\text { Abstract }}$
The aerodynamic performance of a solid uncooled version of a cooled radial turbine was evaluated in the Small Engine Components Test Facility Turbine rig at the NASA Lewis Research Center. Specifically, an experiment was conducted to measure rotor surface static pressures. This was the first time surface static pressures had been measured on a radial turbine at NASA Lewis. These pressures were measured by a modified Rotating Data Package (RDP), a standard product manufactured by Scanivalve, Inc. This report describes the RDP, and the modifications that were made, as well as the checkout, installation, and testing procedures. The data presented are compared to analytical results obtained from NASA's MTSB (MERIDL/TSONIC/BLAYER) code.
\end{abstract}

\section{$\underline{\text { Introduction }}$}

An evaluation of the aerodynamic performance of a solid version of a cooled radial turbine (Fig. 1) was recently conducted in the Small Engine Components Test Facility (SECTF) at the NASA Lewis Research Center. NASA and the Army designed both the solid and cooled versions, and the Allison Gas Turbine Division of General Motors Corporation ${ }^{1}$ modified and fabricated them. The solid rotor was used to obtain baseline performance data for comparison with measurements taken from the cooled version. The performance evaluation of the radial turbine included an

Member AIAA. experiment that measured rotor surface static pressures in a rotating environment. This experiment was conducted to provide a first-ever back-to-back comparison of experimental surface pressures to those obtained with NASA's MTSB (MERIDL/ TSONIC/BLAYER) code using the radial inflow turbine configuration. ${ }^{2}$ This report describes the apparatus and procedures used to measure rotor surface static pressures. In addition, some experimental data are presented and compared to calculated values from MTSB.

\section{$\underline{\text { Apparatus }}$}

The research turbine was mounted inside the annular plenum of the SECTF turbine rig (Fig. 2). The SECTF is a very versatile facility; no other facility can combine its pressure, speed, and temperature ranges. ${ }^{3}$ It can be configured to test either axial or radial, cooled or uncooled turbines up to $14 \mathrm{in}$. in diameter. Main components of the facility include inlet and exhaust piping, a natural gas combustor, a chilled air system, an in-line torquemeter, a reduction gearbox, and an eddycurrent dynamometer. The turbine is driven by combustion air supplied by the NASA Lewis 125-psig (9-atm) combustion air system. The natural gas combustor in the supply line can heat the inlet air to $800^{\circ} \mathrm{F}(700 \mathrm{~K})$. After driving the turbine, the air is exhausted to the altitude exhaust system. Exhaust pressures can range down to 2 psia $(0.15 \mathrm{~atm})$. Power produced by the turbine, up to $1250 \mathrm{hp}$ (935 kW), is absorbed by an eddy-current dynamometer. The dynamometer also controls turbine speed, which can range up to $60000 \mathrm{rpm}$. Torque is measured by an 
inline torquemeter that can be configured to measure up to $427 \mathrm{ft}-\mathrm{lb}(576 \mathrm{~N}-\mathrm{m})$.

Instrumentation was located at six stations along the flowpath (Fig. 3). Instrumentation included rakes to measure total pressure and temperature; static pressure taps on the end walls and the stator blades; traverse probes to measure total pressure, temperature, and flow angle; and tipclearance probes. There were also 36 static taps on the rotor surface itself (Fig. 4). Along two streamlines, 14 surface pressure taps were placed on the suction side of the blade, and 14 taps were placed on the pressure side along the same streamlines. The remaining eight taps were placed along the hub of the rotor. Electron discharge machining (EDM) was used to make trenches on the rotor surface into which stainless steel static pressure tubing was expoxied, thereby leaving the rotor surface smooth. The tubing was terminated at the hub to make a clean interface with the device that was used to measure these pressures while the rotor was spinning.

That device was a Rotating Data Package (RDP), a standard product manufactured by Scanivalve, Inc.; it was specially modified by NASA to meet the requirements of this experiment. Originally, the RDP was designed to measure up to 36 pressures and up to 36 temperatures sequentially. The RDP used pneumatic control signals to step to the next port to read the next research pressure and temperature.

The pressures were measured by a pressure transducer mounted in the stationary environment. The 36 static pressures were carried through tubing to the RDP, where the RDP used a mechanical multiplexer to transfer the selected pneumatic signal to a signal tube mounted on the RDP's centerline. The signal tube, which rotated at turbine speed, was the device that actually transferred the pressures from the rotating to the stationary environment. O-rings mounted on the signal tube provided the necessary seals, and the signal tube carried the pressures to a cavity, where the pressure transducer measured them.

Originally, the rotor surface temperatures were to be measured with thermocouples. The
RDP had thermocouple alloy wires that were to be connected to these thermocouples. The signals were multiplexed in the rotating environment by a wafer switch. The RDP used two pairs of brushes and commutators to transfer the signals from the rotating to the stationary environment. However, noise problems prevented the use of the RDP to measure temperature, thus enabling the thermocouple lines to be used for another purpose.

Since the RDP controller did not provide feedback to read the current RDP port position, a series resistor network was fabricated and mounted in the rotating environment. The unused thermocouple leads were connected to this network. A schematic of the overall resistor network can be found in Fig. 5. As can be seen from this schematic, every time the RDP stepped to the next port, another series resistor was added to the circuit as measured at the output terminals of the RDP. This pattern of adding series resistance was repeated for every port until the RDP reached port 36 , when it would read a direct short circuit between the output terminals when stepped to port 1. By using the series resistor network and a constant voltage source, the current through the $3.889-\mathrm{k} \Omega$ nonrotating shunt resistor varied only with the RDP port position. Thus, by measuring the voltage across the $3.889-\mathrm{k} \Omega$ resistor, a reliable method of measuring the RDP port position was derived. The equation for the position is

$$
\begin{aligned}
\mathrm{N}=\left(-2.8895+\frac{100}{2.571 \mathrm{~V}_{\text {out }}}\right) \\
\\
\text { rounded to the nearest integer }
\end{aligned}
$$

where $\mathrm{N}$ is the port number and $\mathrm{V}_{\text {out }}$ is the voltage across the $3.889-\mathrm{k} \Omega$ resistor.

Prior to the installation, the modified RDP was bench checked for correct stepping, position signals, and pneumatic signals. A known pressure was applied to each port at the hub (which mated to the rotor) and was displayed on the data acquisition system. The computer software and hardware required to operate the RDP was also checked at this time. The port position network 
showed that the RDP was stepping every time the step command was sent.

On initialization, the computer software created an array of dimension 36, which would contain the port pressures. The software also prompted the user for the initial position. A port position counter was defined in the software and was initialized to the user input initial position. When the RDP stepped, the position counter was set to the last port position plus 1 ; it was reset to 1 if the last port position was 36 . The software used to acquire data was written to step to the next port, wait a certain delay time, and read the pressure and the port position from the position network. The port position from the network was then compared to the position counter. If the measured position (from the network) was different from the calculated position (form the port position counter), the software assumed that the RDP had stepped and given an erroneous port position signal, and the software would output a message to the user showing the error. The measured pressure was then input into the array position defined by the position counter.

The method of executing the data acquisition algorithm proved to be useful. At certain times while the RDP was rotating, the port position signal would not show the expected position. For example, the position signal would be incorrect for ports 30 to 34 . However, when the RDP stepped to port 35 , the port position signal again agreed with the port position counter in the computer software. The loss of the position signal was attributed to the vibration of the rotating components in the facility. For the most part, the port position counter agreed with the port position from the position network.

Although the RDP had been dynamically balanced by Scanivalve, since instrumentation had been added, the assembly had to be rebalanced with its mating hardware. The desired tolerance, however, could not be obtained because of the design of the flexible coupling. As an alternative, the RDP was mated to the rotor, and field balancing was attempted. Although the desired tolerance was not achieved, vibrations were reduced enough to obtain strong signals from the resistor network. The RDP was then mated to the rotor and testing began. Testing time was limited in order to minimize any damage potential. Figure 6 shows the RDP installed in the SECTF.

\section{$\underline{\text { Test Analysis }}$}

The test conditions for the RDP experiment consisted of a range of stage pressure ratios and rotational speeds. Since the computational analysis was made at design conditions (stage pressure ratio $=4: 1$ and rotational speed $=19500 \mathrm{rpm}$ ), the discussion of results focuses on the design condition. The RDP system measured the surface static pressures in rotation. A correction for centrifugal pumping was then made to relate the measured pressures to the axis of rotation. ${ }^{4}$ The pressure correction is a solution of the governing differential equation in terms of radius, temperature, and rotational speed. The corrected pressures were determined by the following equation:

$$
P_{(r, \text { corr })}=P_{r i} \exp \left[\frac{\omega^{2}\left(r_{i}^{2}-r_{o}^{2}\right)}{2 R T g_{c}}\right]
$$

where

$\mathrm{P}_{\text {ri }}$ measured static pressure at port i, psi

$\omega$ rotational speed, $\mathrm{rad} / \mathrm{sec}$

$r_{i}$ radial distance of port $i$ to the shaft centerline, $\mathrm{ft}$

$r_{o}$ radial location of the transducer, $\mathrm{ft}$

$\mathrm{R}$ gas constant, ft-lbf/lbm-R

$\mathrm{T}$ average (see note) of inlet and exit total temperature, ${ }^{\circ} \mathrm{R}$

$\mathrm{g}_{\mathrm{c}}$ conversion constant, $32.174 \mathrm{lbm}-\mathrm{ft} / \mathrm{lbf}-\mathrm{sec}^{2}$

NOTE: Because an isothermal process was assumed in deriving this correction and since the surface static temperature at location $r_{i}$ was not available, an average gas temperature was used. 
The corrected pressure was then divided by the averaged total inlet pressure obtained from the inlet rakes. The surface pressure in this ratioed form $\left(\mathrm{P}_{\mathrm{s}} / \mathrm{P}^{\prime} \mathrm{O}\right)$ is compared to the calculations.

The analysis method used to calculate the test point for comparison with the experimental data incorporates the coupling of three computer codes, MERIDL, TSONIC, and BLAYER, as described by Boyle, Haas, and Katsanis. ${ }^{3}$ MERIDL, an inviscid two-dimensional flow code, calculates a midchannel solution from hub to shroud. Using the stream sheet thickness generated by MERIDL, TSONIC (also a two-dimensional code) calculates blade-to-blade stream surfaces at user specified locations from hub to tip. Using the resulting quasi-three-dimensional solution as input, BLAYER, an integral method boundary layer code, calculates the boundary layer growth along all four flow channel surfaces. MTSB is a robust, well-used code for the axial turbine configuration, but it has seen little application to the radial configuration.

Figures 7 to 9 compare the MTSB analysis results and the experimental data. First, Fig. 7 compares the nonrotating stator data to the calculated data. One streamline is represented because the stator has a constant cross section along the z-axis. For this straightforward case, the MTSB solution is shown to be highly accurate compared to the experimental data. The solution accurately depicts the spike due to a surface curvature inflection that occurs near the stator throat region. This spike persists even at lower pressure ratios where the flow is subsonic. ${ }^{6}$ Figure 8 shows the rotor solution of the streamline at 20-percent span compared with the measured values, and Fig. 9 shows the solution at the 70-percent streamline. Figure 8 shows that MTSB overpredicts the surface pressures at the inlet, particularly on the pressure side. The overprediction appears to be more significant on the 20-percent streamline than on the 70-percent streamline.

As shown in Fig. 1, the rotor has a scalloped backface. The first four surface pressure taps on the 20 -percent streamline are radially located on or within this scalloped region. They show the greatest variation between calculation and measurement.
Additionally, the backface clearance for this rotor was extremely large at 0.058 in. as compared with tip clearances of approximately $0.016 \mathrm{in}$. The scalloped backface and the large backface clearance allow the higher pressure flow on the pressure side of the blade to leak around to the suction surface. The solution for the 70-percent streamline shows much better agreement with the measured values. If the flow is leaking around the scalloped backface, the effect is not as pronounced toward the shroud region.

References 5 and 6 compare the calculated clearance loss breakdown with the measured losses. MTSB accurately predicts the overall loss for this turbine (with the clearance losses dominating), but the clearance loss correlation predicts smaller clearance losses than are measured. The secondary flow effects associated with the scalloped backface and large backface clearance cannot be accurately calculated with MTSB because it is not a truly three-dimensional viscous code. The RDP provided data that accurately illustrate the limitations of this code. The information obtained from the analysis also highlights the need for more data on the effect of tip- and backface-clearance gap sizes. With the tip- and backface-clearance data, MTSB can employ a more accurate clearance loss model.

\section{Concluding Remarks}

Although results from the experiment were useful, working with the RDP was difficult. Noise problems prohibited rotor surface temperature measurement, and rig vibrations caused errors in the port position readout. Steady-state rig conditions were required during the 3 min needed to complete a survey. Furthermore, the controller unit was unable to sample at a given port for a user defined length of time. It was also unable to determine port position and could not accept a user specified port. To overcome this deficiency, the series resistor network and control software was designed and implemented.

The system described herein is a viable means for obtaining pressures from a rotor surface. However, there are now other options available for obtaining pressures in a rotating environment. One such scheme consists of mounting miniature pressure transducers on the surface of the rotor. A 
slip ring could then be used to transfer the electrical signals from the rotating to the stationary environment. Another possibility would be to use an electronically scanned pressure module with a slip ring. When experiments require obtaining pressure data from a rotating environment, consider these options as well as anticipated future technological improvements.

\section{$\underline{\text { References }}$}

${ }^{1}$ Snyder, P.H.; and Roelke, R.J.: The Design of an Air-Cooled Metallic High Temperature Radial Turbine. AIAA Paper 88-2872, 1988.

${ }^{2}$ Boyle, R.J.; Haas, J.E.; and Katsanis, T.: Comparison Between Measured Turbine Stage Performance and Predicted Performance Using Quasi-3D Flow and Boundary Layer Analyses. NASA TM-83640, 1984.
${ }^{3}$ Nowlin, B.C.; and Verhoff, V.G.: Small Engine Components Test Facility Turbine Testing Cell. AIAA Paper 88-2962, 1988.

${ }^{4}$ Chivers, J.W.H.: Blade Pressure Measurements. Measurement Techniques in Turbomachines, Von Karman Institute for Fluid Dynamics. Rhode-Saint-Genese, Belgium, 1981, p. 21.

${ }^{5}$ Simonyi, P.S.; and Boyle, R.J.: Comparison of Analysis and Experimental Performance for Three Compact Radial Turbines. AIAA Paper 91-2128, 1991.

${ }^{6}$ Tirres, L.: A Comparison of the Analytical and Experimental Performance of the Solid Version of a Cooled Radial Turbine. NASA CR-187195, 1991.

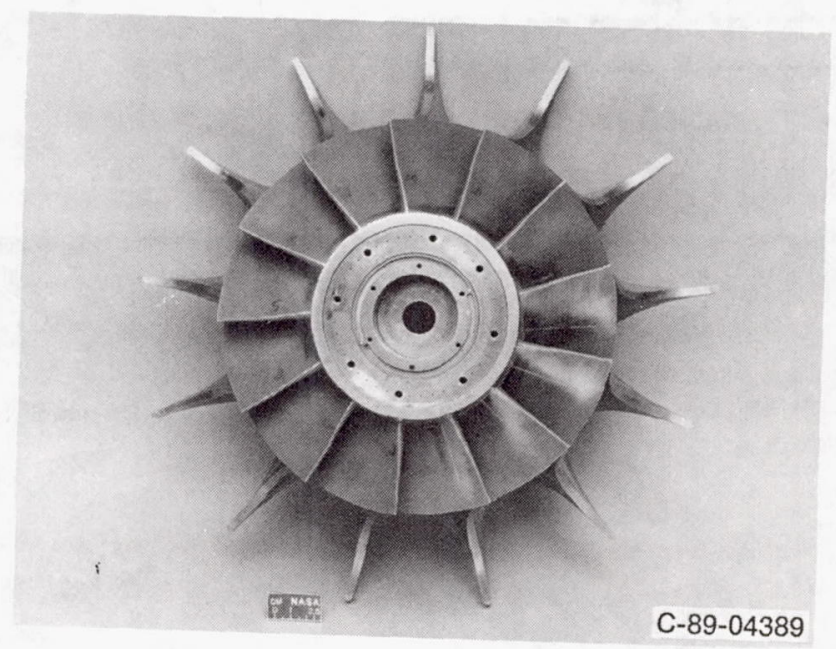

Fig. 1 Solid version of cooled radial turbine. 


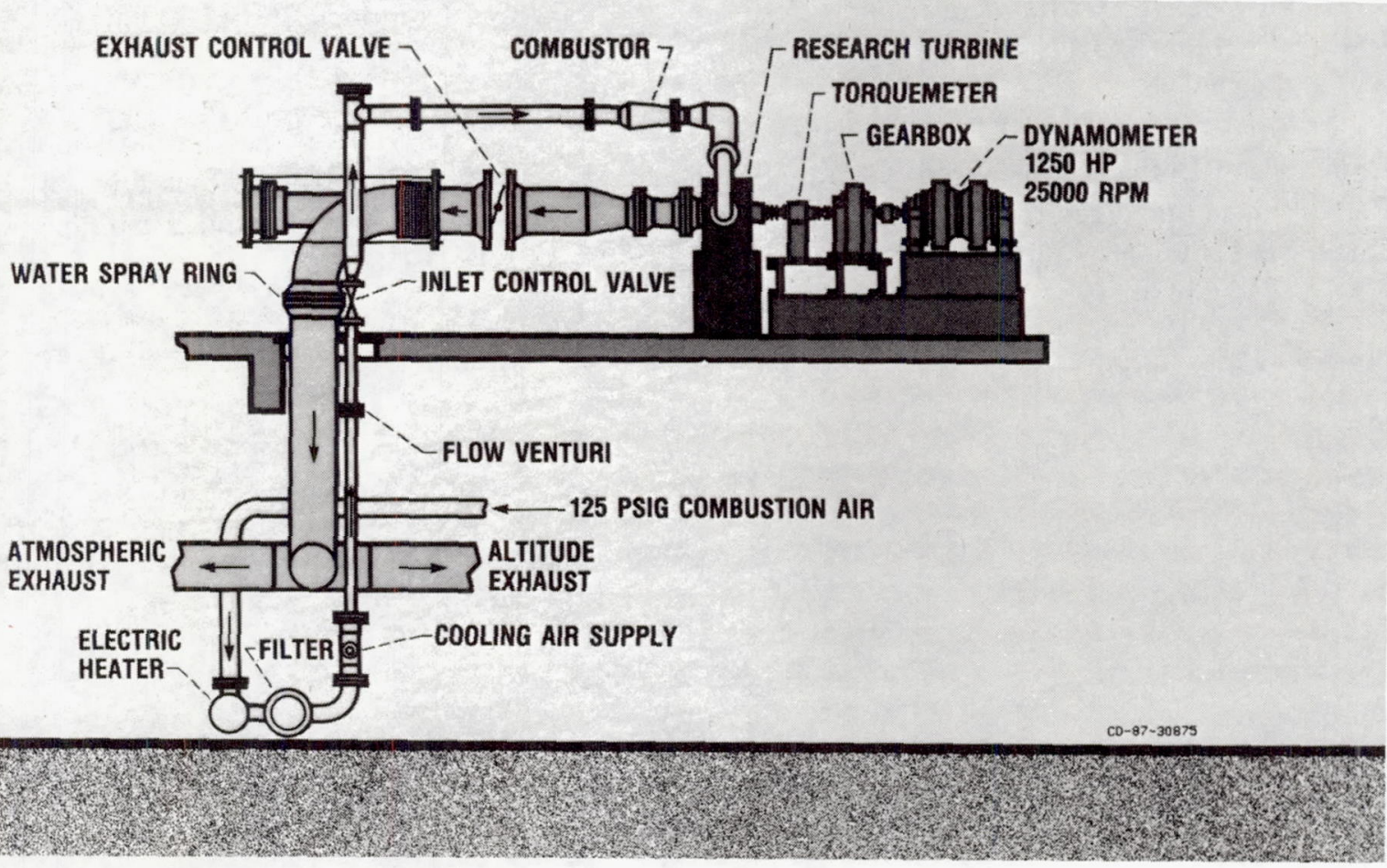

Fig. 2 NASA Lewis Research Center Small Engine Components Turbine Test Facility. 


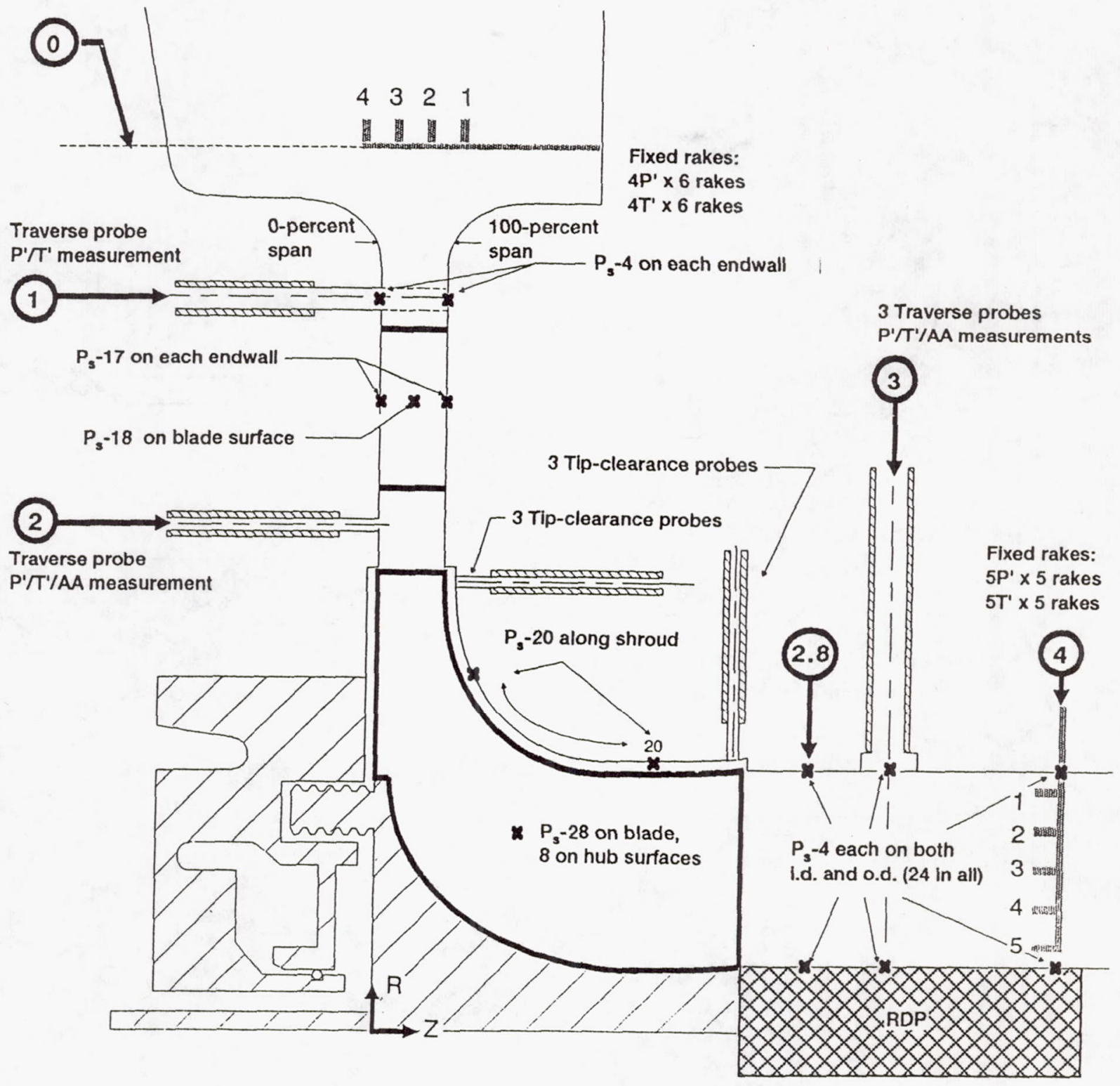

Flg. 3 Research hardware instrumentation locations. 


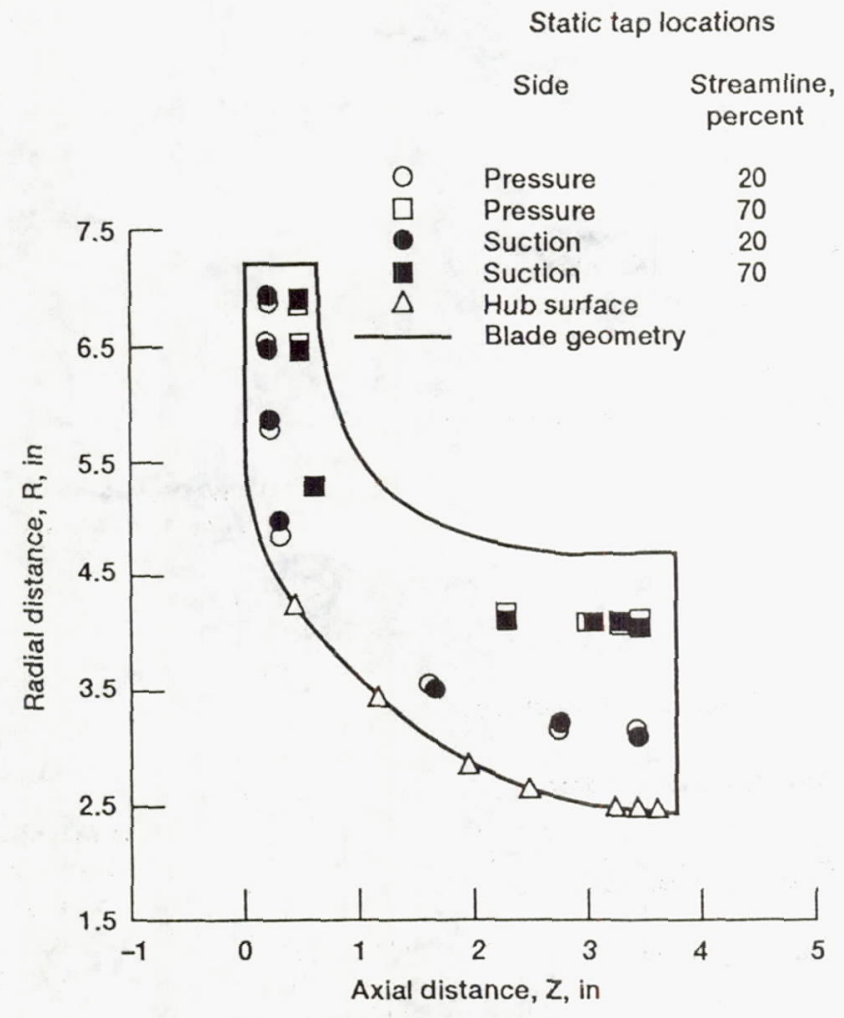

Fig. 4 Location of static taps.

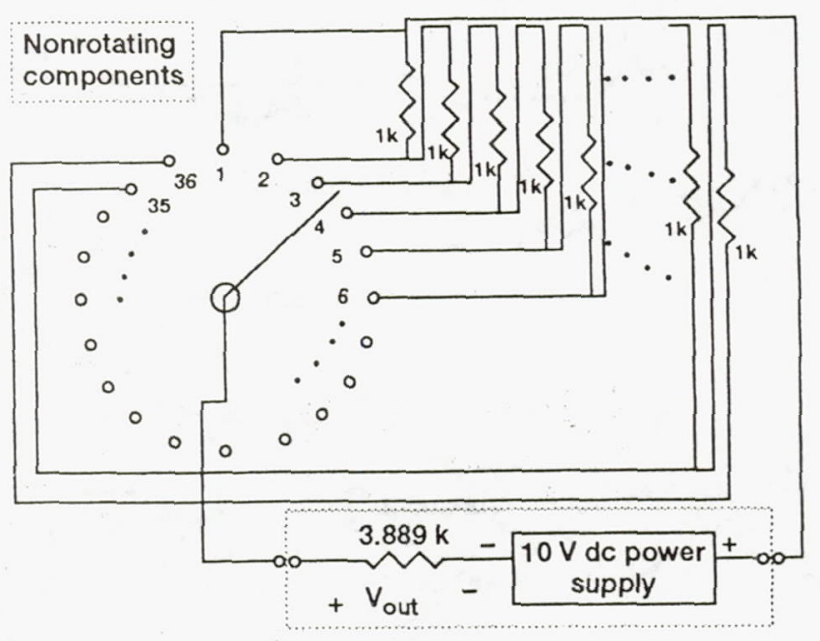

Fig. 5 Series resistor network.

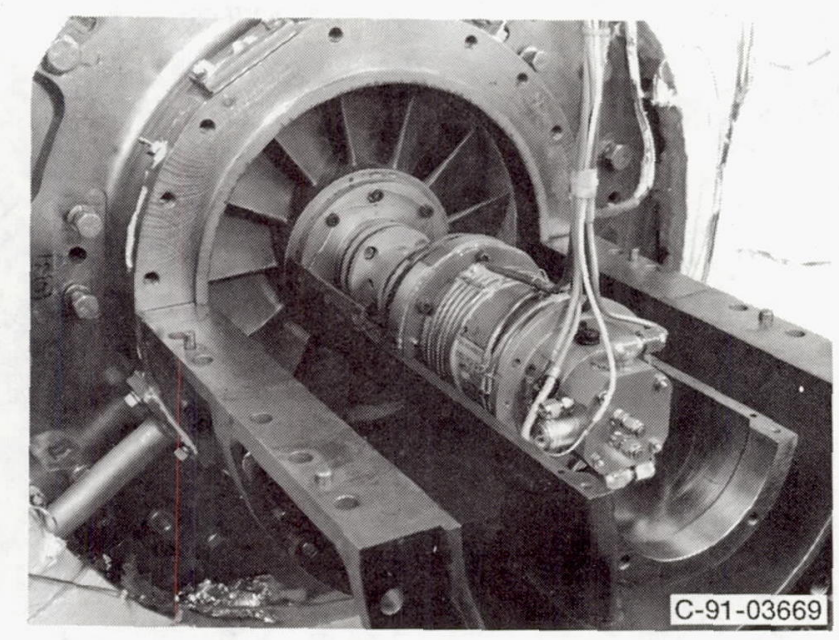

Fig. 6 RDP installed in the Small Engine Components Turbine Test Facility. 


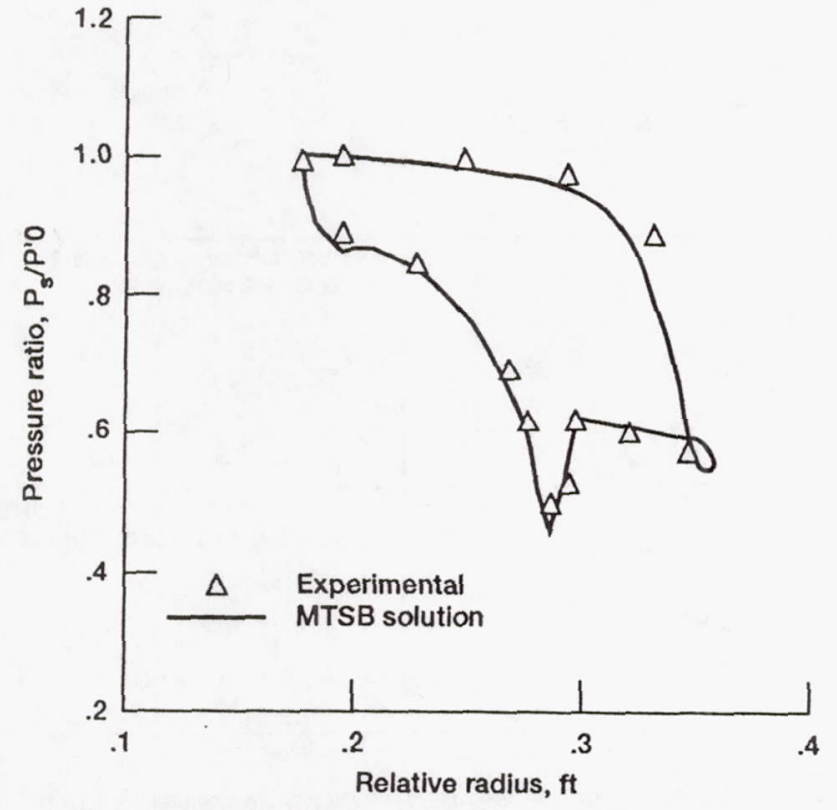

Fig. 7 Comparison of measured and calculated stator pressures at design conditions.

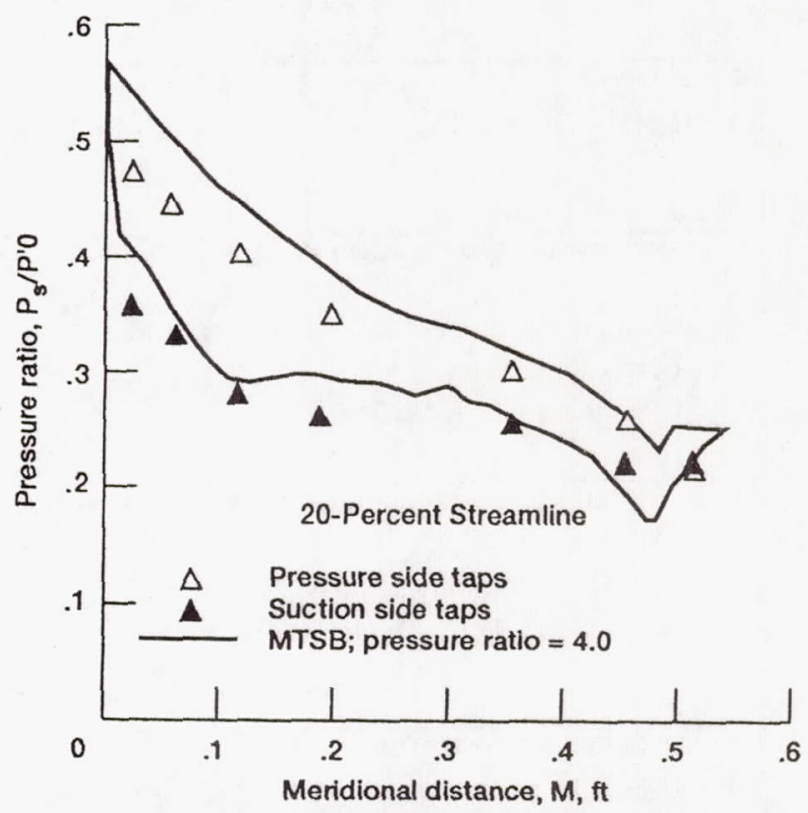

Fig. 8 At 20-percent streamline, comparison of measured and calculated ratioed rotor pressures with respect to meridional distance.

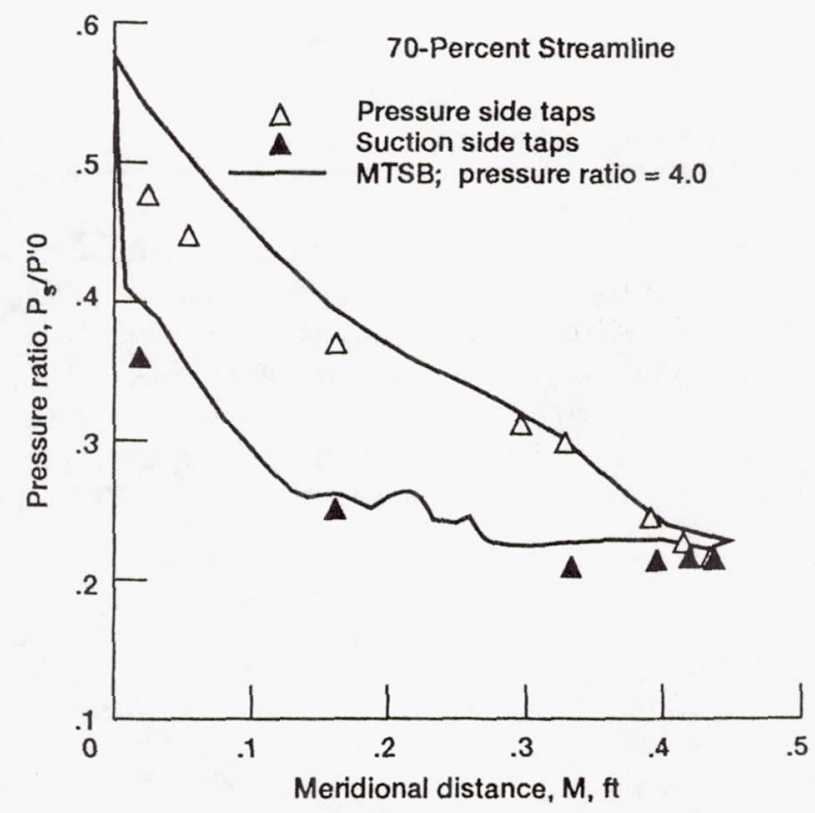

Fig. 9 At 70-percent streamline, comparison of measured and calculated raticed rotor pressures with respect to meridional distance. 
Public reporting burden for this collection of information is estimated to average 1 hour per response, including the time for reviewing instructions, searching existing data sources, gathering and maintaining the data needed, and completing and reviewing the collection of information. Send comments regarding this burden estimate or any other aspect of this collection of information, including suggestions for reducing this burden, to Washington Headquarters Services, Directorate for information Operations and Reports, 1215 Jefferson Davis Highway, Suite 1204, Arlington, VA 22202-4302, and to the Office of Management and Budget, Paperwork Reduction Project (0704-0188), Washington, DC 20503.

\begin{tabular}{|l|c|c|}
\hline 1. AGENCY USE ONLY (Leave blank) & $\begin{array}{c}\text { 2. REPORT DATE } \\
1992\end{array}$ & $\begin{array}{r}\text { 3. REPORT TYPE AND DATES COVERED } \\
\text { Technical Memorandum }\end{array}$ \\
\hline
\end{tabular}

4. TITLE AND SUBTITLE

5. FUNDING NUMBERS

Description of a Pressure Measurement Technique for Obtaining Surface

Static Pressures of a Radial Turbine

6. AUTHOR(S)

L. Danielle DiCicco, Brent C. Nowlin, and Lizet Tirres

WU-535-05-10

\section{PERFORMING ORGANIZATION NAME(S) AND ADDRESS(ES)}

National Aeronautics and Space Administration

Lewis Research Center

Cleveland, Ohio 44135-3191
8. PERFORMING ORGANIZATION REPORT NUMBER

E-6989

10. SPONSORING/MONITORING AGENCY REPORT NUMBER

NASA TM-105643

AIAA-92-4006

\section{SUPPLEMENTARY NOTES}

Prepared for the 17th Aerospace Ground Testing Conference sponsored by the American Institute of Aeronautics and Astronautics, Nashville, Tennessee, July 6-8, 1992. L. Danielle DiCicco and Brent C. Nowlin, NASA Lewis Research Center; Lizet Tirres, Sverdrup Technology, Inc., Lewis Research Center Group, 2001 Aerospace Parkway, Brook Park, Ohio 44142. Responsible person, L. Danielle DiCicco, (216) 433-5656.

\section{2a. DISTRIBUTION/AVAILABILITY STATEMENT}

Unclassified - Unlimited

Subject Category 35 12b. DISTRIBUTION CODE

\section{ABSTRACT (Maximum 200 words)}

The aerodynamic performance of a solid uncooled version of a cooled radial turbine was evaluated in the Small Engine Components Test Facility Turbine rig at the NASA Lewis Research Center. Specifically, an experiment was conducted to measure rotor surface static pressures. This was the first time surface static pressures had been measured on a radial turbine at NASA Lewis. These pressures were measured by a modified Rotating Data Package (RDP), a standard product manufactured by Scanivalve, Inc. This report describes the RDP, and the modifications that were made, as well as the checkout, installation, and testing procedures. The data presented are compared to analytical results obtained from NASA's MTSB (MERIDL/TSONIC/BLAYER) code.

\begin{tabular}{|c|c|}
\hline $\begin{array}{c}\text { 14. SUBJECT TERMS } \\
\text { Radial turbine; Pressure measurement }\end{array}$ \\
\hline $\begin{array}{c}\text { 17. SECURITY CLASSIFICATION } \\
\text { OF REPORT } \\
\text { Unclassified }\end{array}$ & $\begin{array}{c}\text { 18. SECURITY CLASSIFICATION } \\
\text { OF THIS PAGE } \\
\text { Unclassified }\end{array}$ \\
\hline
\end{tabular}

\begin{tabular}{|c|c|}
\hline & $\begin{array}{l}\text { 15. NUMBER OF PAGES } \\
12\end{array}$ \\
\hline & $\begin{array}{r}\text { 16. PRICE CODE } \\
\mathrm{AO} 3\end{array}$ \\
\hline $\begin{array}{l}\text { 19. SECURITY CLASSIFICATION } \\
\text { OF ABSTRACT } \\
\text { Unclassified }\end{array}$ & 20. LIMITATION OF ABSTRACT \\
\hline & $\begin{array}{l}\text { ndard Form } 298 \text { (Rev. 2-89) } \\
\text { scribed by ANSI Std. Z39-18 } \\
102\end{array}$ \\
\hline
\end{tabular}



National Aeronautics and

Space Administration

Lewis Research Center

Cleveland, Ohio 44135

Official Business

Penalty for Private Use $\$ 300$
Postage and Fees Pard National Aeronautics and Space Administration NASA 45 